\title{
Structural FTIR analysis of cellulose functional groups isolated from Leucaena leucocephala pods using different bleaching agents
}

\author{
Aida Safina Aridia, Chin Nyuk Ling ${ }^{\mathrm{a}}$, Nur Akmal Ishak ${ }^{\mathrm{b}}$, Nor Nadiah Mohammad Yusof ${ }^{\mathrm{c}}$, \\ Mohamed Fikry Mohamed Ahmed ${ }^{d}$. and Yus Aniza Yusofa* \\ ${ }^{a}$ Department of Process and Food Engineering, Faculty of Engineering, Universiti Putra \\ Malaysia,Serdang, 43400, Selangor, Malaysia. \\ bBiology Unit, Centre of Foundation Studies for Agricultural Science, Universiti Putra \\ Malaysia, Serdang, 43400, Selangor, Malaysia \\ 'Polymer Engineering Technology, Universiti Kuala Lumpur Malaysia Institute of Chemical \\ and Bio-engineering Technology, Alor Gajah, 78000, Melaka, Malaysia \\ ${ }^{\mathrm{d} D e p a r t m e n t}$ of Biosystems and Agricultural Engineering, Faculty of Agriculture, Benha \\ University, 13736 Moshtohor, Toukh, Qalyoubia, Governorate, Egypt. \\ *Corresponding author: yus.aniza@upm.edu.my
}

\begin{abstract}
In this study, extracted cellulose fibres were successfully isolated from Leucaena leucocephala pods through an efficient alkaline treatment and bleaching method using different bleaching agents such as 5 wt.\% of sodium chlorite $\left(\mathrm{NaClO}_{2}\right), 5$ wt.\% of oxalic acid $\left(\mathrm{C}_{2} \mathrm{H}_{2} \mathrm{O}_{4}\right), 5$ wt. $\%$ of potassium permanganate $\left(\mathrm{KMnO}_{4}\right)$ and $5 \mathrm{wt} . \%$ of sodium hypochlorite $(\mathrm{NaClO})$, respectively. The functional group of the cellulose fibres were analysed by using attenuated total reflection infrared (ATR-IR) spectroscopy. The ATR-IR spectra reported that the Leucaena leucocephala fibres after being given chemical treatment with $5 \% \mathrm{w} / \mathrm{w}$ of $\mathrm{NaClO}$ lead the similar functional group with the commercial cellulose due to removal hemicellulose and lignin. The content cellulose of final product was $89.4 \%$ was measured by the chemical composition test. Meanwhile, the whiteness index of Leucaena leucocephala fibres treated with 5 wt. $\% \mathrm{NaClO}$ was $78.5 \%$, which was the highest. The results of ATR-IR, chemical composition test and whiteness index were indicated that the sample of Leucaena leucocephala pods presents the structure of cellulose.
\end{abstract}

Keywords: Leucaena leucocephala, cellulose, alkaline treatment, bleaching method, FTIR, agriculture waste

\section{Introduction}

Cellulose is a natural polymer that can be isolated from the plant. It is the plant cell wall materials, together with hemicellulose and lignin. These natural polymers can be used for the production of paper and textiles, and it also can be modified into carboxyl methylcellulose (CMC) which can be used as additives in food products (Aurelia, Murdiati, \& Ningrum, 2019) (Aurelia et al., 2019). The isolation of cellulose from new sources, especially agricultural waste and underutilized plants is attractive both economically and environmentally. This is because most of the agricultural waste is disposed of by burning or burying (Zafar, 2019), and it can cause air pollution. It is crucial to find a better method to dispose of waste. The trends of using waste from agriculture such as rice straw (Musa, Ahmad, \& Hussein, 2017), sugarcane bagasse 
(Plermjai, Boonyarattanakalin, \& Mekprasart, 2018), pineapple peels (Camacho et al., 2017), have been increased for the source of cellulose.

Besides, there also some research that identified the underutilized plant to be used as a source for cellulose. Husin et al., (2017) was successfully isolated cellulose and microcrystalline cellulose from Leucaena leucocephala seeds obtained as waste from biodiesel production. The yield of cellulose obtained was $33 \%$. Moreover, previous research had investigated the cellulose isolation from Leucaena leucocephala seeds (Aini et al., 2019). Cellulose was successfully isolated from the seeds, and the crystallinity index of cellulose obtained was $76.04 \%$. Thus, it proved that Leucaena leucocephala plants have the potential to be used as the source for cellulose isolation.

In 2012, the government of Malaysia has identified Leucaena leucocephala or also known as "Petai belalang" as one of the energy plants and would soon form part of the country's landscape similar to oil palm, and rubber (Adnan, 2012). The leave produced an excellent forage as it contains a high amount of protein. The forage production from this plant provides metabolic protein supplies with a well-balanced amino acid to the animal (Soltan, Morsy, Lucas, \& Abdalla, 2017).

Fourier transform infrared spectroscopy (FTIR) with attenuated total reflection (ATR) unit is one of the most commonly used methods for identification different functional groups constituting a compound. It is a rapid and non-destructive technique for the qualitative and quantitative determination of biomass components in the midIR region (Xu, Yu, Tesso, Dowell, \& Wang, 2013). The FTIR spectroscopy provides information about molecular fragments, the functional groups and can give deeper insight into the Leucaena leucocephala fibres structure. Thus, the aim of this paper was to comparative FTIR investigation of extracted cellulose fibres from Leucaena leucocephala pods using different bleaching agents which are sodium chlorite $\left(\mathrm{NaClO}_{2}\right)$, sodium hypochlorite $(\mathrm{NaClO})$, oxalic acid $\left(\mathrm{C}_{2} \mathrm{H}_{2} \mathrm{O}_{4}\right)$, and potassium permanganate $\left(\mathrm{KMnO}_{4}\right)$.

\section{Materials and methods}

Figure 1 summarizes the main steps of the present methodology. Mature Leucaena leucocephala pods were collected from trees available at Universiti Putra Malaysia. The pods collected were brown, and the size of the pods was a range 
between 14 to $18 \mathrm{~cm}$ long. They were washed thoroughly using tapped water and then were dried using a drying oven (Memmert Universal Oven, German) for $24 \mathrm{~h}$ at $100^{\circ} \mathrm{C}$ before ground into fiber using a miller machine (Laboratory Mill 120, Perten, Sweden). All the chemicals used in this research were analytical grade and applied without further purification.

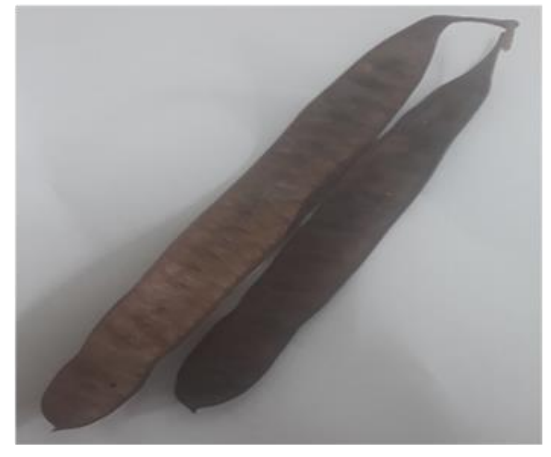

Leucaena leucocephala $(L L)$ mature pod

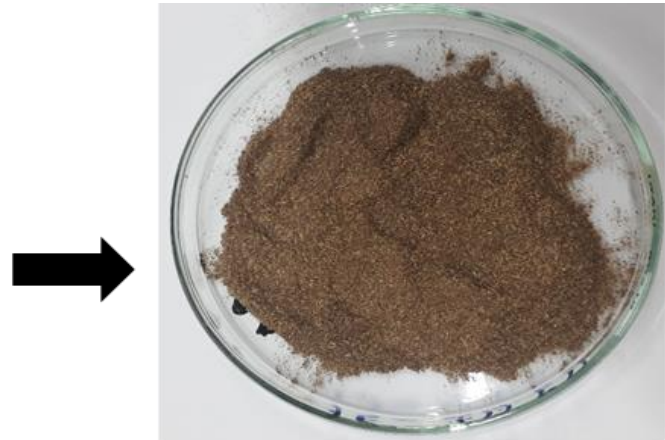

Leucaena leucocephala powder
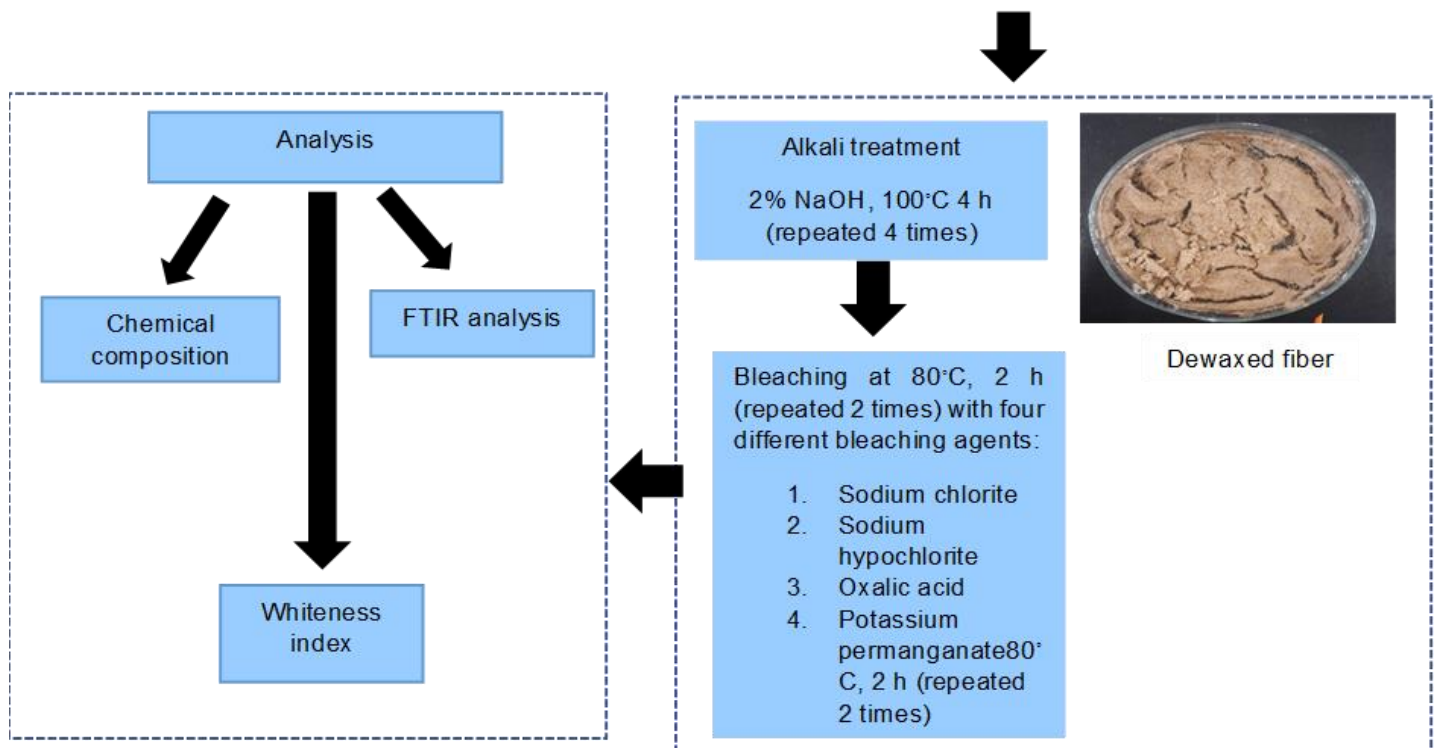

Figure 1: Flowchart of the methodology aimed to investigate the effect of different bleaching agents to the characterization of cellulose isolated from Leucaena leucocephala fiber.

\subsection{Alkaline treatment of Leucaena Leuocephala pods}

The alkaline treatment was performed using the method described by (Zheng, Zhang, Guo, \& Yue, 2019). This treatment aimed to eliminate hemicellulose from the Leucaena leucocephala pods to obtain purified cellulose. The fiber was mixed with 2 wt.\% of sodium hydroxide $(\mathrm{NaOH})$ solution in a solid-to-liquid ratio of $1 \mathrm{~g} / 10 \mathrm{ml}$, 
shaken at $50 \mathrm{rpm}$, and heated at $100^{\circ} \mathrm{C}$ in a shaking water bath for 4 hours. This alkali treatment was repeated four times until no more discoloration occurred. Then, the fiber was washed with distilled water until $\mathrm{pH} 7$ and proceed to the second pre-treatment.

\subsection{Bleaching treatment}

Bleaching process involved the removal of lignin and other components by stirring the lignocellulosic material with a mixture of bleaching agents. In this study, four types of bleaching agents were used to determine which bleaching agent is the best to remove lignin to obtain purified cellulose. $\mathrm{NaClO}_{2}$ (5 wt.\%), $\mathrm{C}_{2} \mathrm{H}_{2} \mathrm{O}_{4}$ (5 wt.\%), $\mathrm{KMnO}_{4}$ (5 wt.\%), and $\mathrm{NaClO}$ (5 wt.\%) were used to remove the lignin group from the mature Leucaena leucocephala fiber. The solid-to-liquid ratio used was $1 \mathrm{~g}$ of fiber to $50 \mathrm{ml}$ of bleaching agent solution. The solution was then heated at $80^{\circ} \mathrm{C}$ and shaken at 100 rpm for 2 hours using a shaking water bath and repeated two times to obtain a white fiber. The bleached fiber was then thoroughly washed using distilled water until $\mathrm{pH} 7$ was obtained.

\subsection{Analysis of chemical composition}

The lignin content was determined according to the TAPPI norm T222 om-88 (Song, Zhu, Zhu, \& Li, 2019). One g of the fiber was added into $15 \mathrm{~mL}$ of sulphuric acid $\left(\mathrm{H}_{2} \mathrm{SO}_{4}\right)$ with the percentage of acid was 72 wt.\%. The solution was then maintained at room temperature for 2 hours. After that, $560 \mathrm{ml}$ of distilled water was added and the solution was then boiled for 4 hours before centrifuge to obtain the insoluble lignin. The obtained lignin was then oven-dried and measure the weight. The percentage of lignin obtained was calculated using Eq. (1).

$$
\text { Lignin }(\%)=\frac{M 1}{M} \times 100
$$

where $M_{1}$ was the obtained lignin mass, $M$ was the initial sample mass.

The percentage of hemicellulose in the fiber was determined according to the TAPPI T257 om-09. Holocellulose content was quantified with $\mathrm{NaClO}_{2}$ treatment according to the procedure reported by Song et al., (2019). $1 \mathrm{~g}$ of fiber was added into a solution, $30 \mathrm{ml}$ containing $0.25 \mathrm{ml}$ of acetic acid and $0.3 \mathrm{~g}$ of $\mathrm{NaClO}$. Then, the mixture was heated at $75^{\circ} \mathrm{C}$ for 1 hour, and cooled down, filtered, and washed with 
water. The residue was then dried and weight, the holocellulose content was calculated using Eq. (2).

$$
\text { Holocellulose }(\%)=\frac{M 2}{M} \times 100
$$

where $M_{2}$ was the obtained residue mass, $M$ was the initial sample mass.

The cellulose content in the fiber was determined by extracting cellulose from the holocellulose with $\mathrm{NaOH}(17.5 \%)$ for 5 hours before stopping the reaction with ice. The obtained white powder was washed with lots amount of water until the filtrate becoming neutral. The percentage of cellulose was calculated using Eq. (3).

$$
\text { Cellulose }(\%)=\frac{M 3}{M} \times 100
$$

where $M_{3}$ was the obtained white powder mass, $M$ was the initial sample mass.

\subsection{Whiteness index}

The reflective surface color of all samples was measured using a color measurement system (Colorimeter Konica, Japan) RSEX (Reflectance Specular Excluded) mode type was used, and the area view was $0.190 \mathrm{inch}$. The value of $L^{*}$, $a^{*}$, and $b^{*}$ were recorded, and each sample was individually measured in triplicates. The whiteness index (WI\%) was calculated using Eq.4 (Yen \& Mau, 2006):

$$
\text { WI }(\%)=100-\left[\left(100-L^{*}\right) 2+\left(a^{\star}\right) 2+\left(b^{\star}\right) 2\right] 1 / 2
$$

Where, $W I$ is the percentage of whiteness index, $L^{*}$ for the lightness from black $(0)$ to white (100), $a^{*}$ from green $(-)$ to red $(+)$, and $b^{*}$ from blue $(-)$ to yellow $(+)$. 


\subsection{Functional group analysis by Fourier Transform Infrared (FTIR)}

The infrared spectroscopy equipped with the ATR technique is an ideal for investigation of the IR solids. In this analysis, potassium bromide $(\mathrm{KBr})$ was used as the diluents. The powder samples and $\mathrm{KBr}$ were grounded to reduce the particle size to less than $5 \mathrm{~mm}$ in diameter. $\mathrm{KBr}$ was added into an agate mortar and ground it to fine powder. Then, the sample was mixed with the $\mathrm{KBr}$ powder, and was ground for 3 to 5 minutes. Next it was added to the $7 \mathrm{~mm}$ collar and press with a small hydraulic press to produce a pellet. The pellet was then put onto the sample holder and begin scanning. The FTIR spectra were then collected at the mid-infrared region (4000 $400 \mathrm{~cm}^{-1}$ ) using 32 scans.

\section{Results and Discussion}

\subsection{Chemical composition}

The chemical composition of Leucaena leucocephala fiber at each stage of chemical treatment are presented in Table 1. The hemicellulose and lignin in the fiber were started to decrease after the alkaline treatment with $\mathrm{NaOH}$. After further treatment during bleaching process, the percentage of hemicellulose and lignin was further reduced. Bleaching treatment with $\mathrm{NaClO}$ shows the lowest percentage of hemicellulose and lignin, with $5.87 \%$ and $1.74 \%$, respectively. This proved that sodium hypochlorite is an efficient bleaching agent in order to remove the non-lignocellulosic materials from the Leucaena leucocephala fiber.

Moreover, previous research (Hayati, Rahman, Chieng, \& Rahman, 2017; Zheng et al., 2019), also showed a similar trend. The percentage of non-cellulosic components in Leucaena leucocephala fiber was started to reduce after the alkaline treatment with $\mathrm{NaOH}$ and bleaching treatment using acidified $\mathrm{NaClO}_{2}$ solution. By the addition of $\mathrm{NaOH}$ and bleaching agent to the delignification process plays a role in separating lignin from the complex lignin-cellulose and in rupturing the anhydrous glucose unit (AGU) linkage in cellulose that results in cellulose weight loss. However, the treatment of Leucaena leucocephala fibers with $\mathrm{NaClO}$ produce the highest cellulose content which was $89.4 \%$, compared with other three bleaching agents. The use of $5 \mathrm{wt} . \% \mathrm{NaClO}$ significantly increased the cellulose yield due to the rupture of 
the lignin linkage in lignin-cellulose complex as shown in the Table 1, which the percentage of lignin obtained was $1.74 \%$. In addition, the $\mathrm{NaClO}$ can oxidize the cellulose specifically in its amorphous zone.

Table 1: Chemical composition of untreated Leucaena leucocephala fiber and treated Leucaena leucocephala fiber.

\begin{tabular}{|l|c|c|c|c|}
\hline \multicolumn{1}{|c|}{ Sample } & $\begin{array}{c}\text { Cellulose } \\
(\%)\end{array}$ & $\begin{array}{c}\text { Hemicellulose } \\
(\%)\end{array}$ & $\begin{array}{c}\text { Holocellulose } \\
(\%)\end{array}$ & Lignin (\%) \\
\hline Untreated fiber & 46.60 & 34.51 & 81.11 & 32.29 \\
\hline $\begin{array}{l}\text { Alkali treated } \\
\text { fiber }\end{array}$ & 62.24 & 20.73 & 82.97 & 18.73 \\
\hline $\begin{array}{l}5 \% \text { sodium } \\
\text { chlorite }\end{array}$ & 65.74 & 12.40 & 78.14 & 10.47 \\
\hline $\begin{array}{l}5 \% \text { sodium } \\
\text { hypochlorite }\end{array}$ & 89.37 & 5.87 & 95.24 & 1.74 \\
\hline 5\% oxalic acid & 46.40 & 20.81 & 67.21 & 30.01 \\
\hline $\begin{array}{l}5 \% \text { potassium } \\
\text { permanganate }\end{array}$ & 46.67 & 18.47 & 65.14 & 40.03 \\
\hline
\end{tabular}

\subsection{Whiteness index}

Cellulose has been used in many applications such as in food packaging. However, the color of the cellulose extracted from the plants was reported to have a natural yellowish-brown. In Figure 2, the color of untreated Leucaena leucocephala fiber was dark brown, and after undergoing the alkaline treatment with $\mathrm{NaOH}$, it turns to light brown. This color is not suitable to be used in many applications as it can affect the final quality of final products, especially if it is used as a food additive. Thus, a bleaching process was conducted to improve the color of fiber obtained, as well as producing a highly purified cellulose.
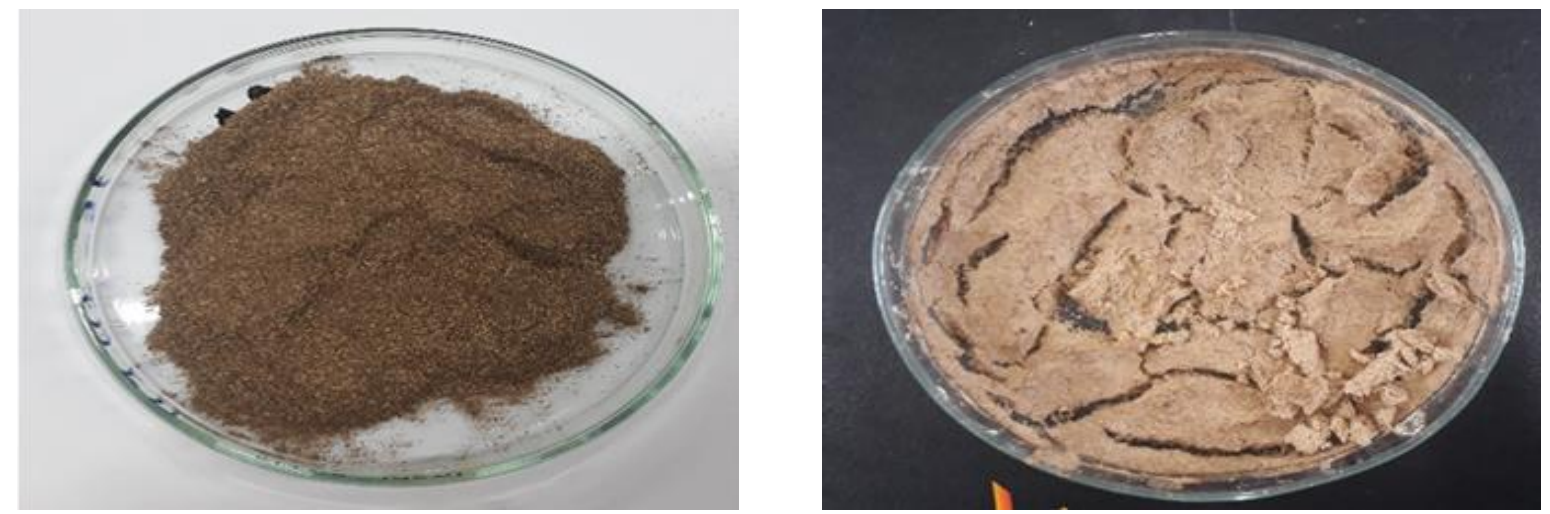

(a)

(b) 

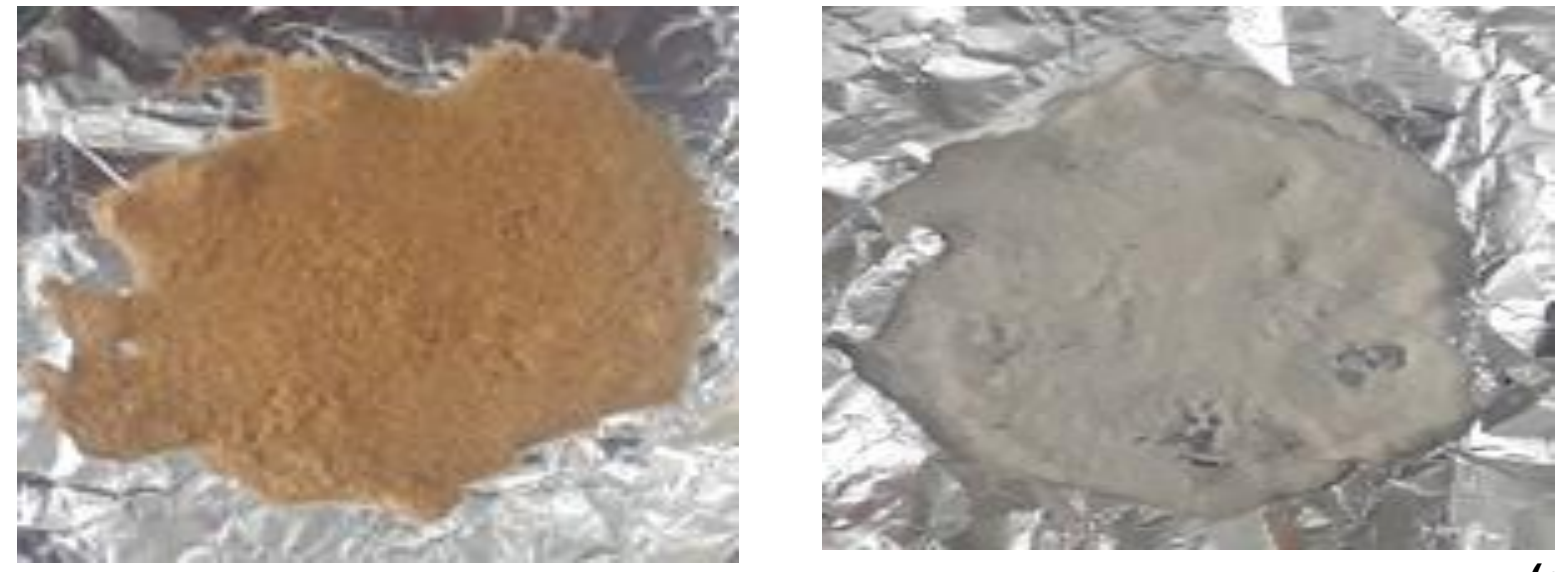

(c)
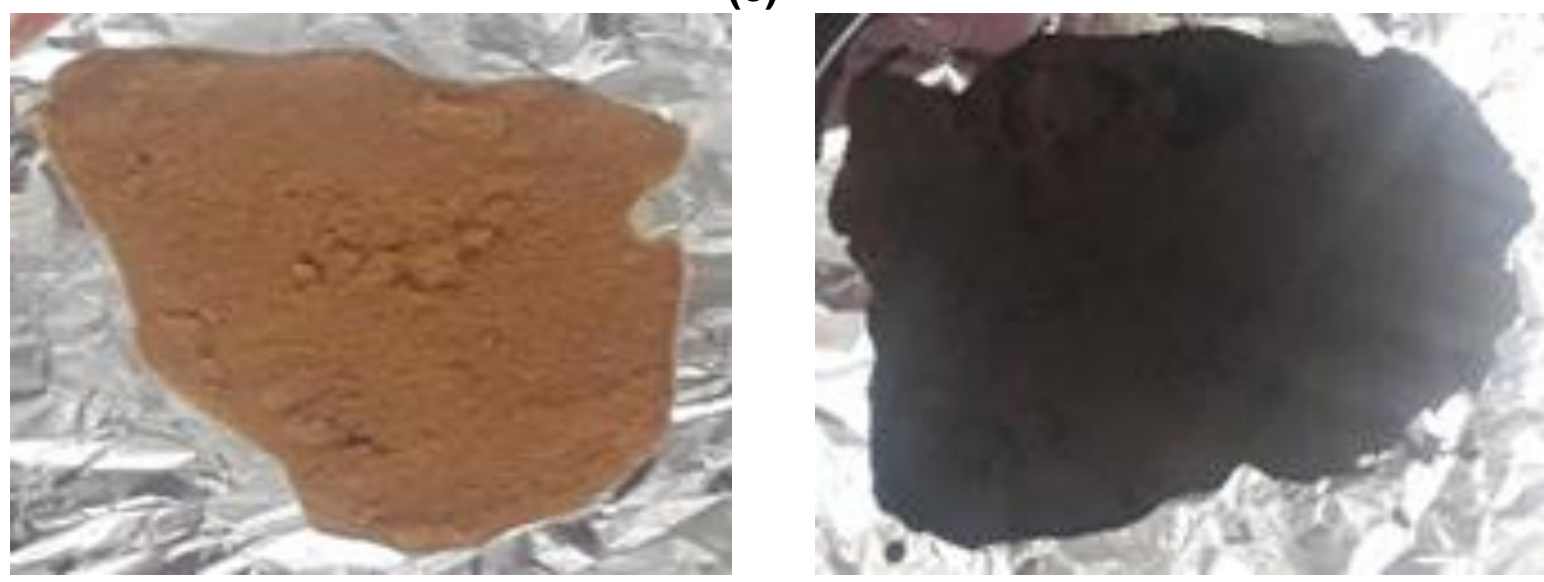

(e)

Figure 2: Isolated cellulose by using different bleaching agents. (a) Untreated Leucaena leucocephala fiber, (b) Alkali treated fiber, (c) Isolated cellulose using 5\% sodium chlorite, (d) Isolated cellulose using $5 \%$ sodium hypochlorite, (e) Isolated cellulose using $5 \%$ oxalic acid, and (f) Isolated cellulose using $5 \%$ potassium permanganate.

In addition, Figure 3 presented the percentage of whiteness index of all samples. Fiber treated with $\mathrm{NaClO}$ has the highest percentage of whiteness index which is $78.5 \%$, and the lowest whiteness index was showed by the fiber treated with $\mathrm{KMnO}_{4}, 45.7 \%$. The change in color in fiber could be contributed by the solubilization of lignin at high temperatures in an alkaline charge (Lee, $\mathrm{Ng}$, \& Law, 2018). Bleaching with $\mathrm{KMnO}_{4}$ showed the lowest whiteness index probably because of lignin was not fully solubilized during the treatment. $\mathrm{KMnO}_{4}$ is a strong oxidizing agent in acid medium, but it is a weak oxidant in the neutral and alkaline medium (Youcai, 2018), and in this study, the $\mathrm{KMnO}_{4}$ used was in its neutral condition.

Moreover, $\mathrm{NaClO}$ is a chlorine compound that is often used as a disinfectant or a bleaching agent. It is widely used during the pre-treatment of fiber to obtain a highly purified cellulose. Furthermore, bleaching with sodium hypochlorite can produce a 
highly purified cellulose (Aurelia et al., 2019). They concluded $3 \% \mathrm{NaClO}$ gives the highest cellulose content, light cellulose color.

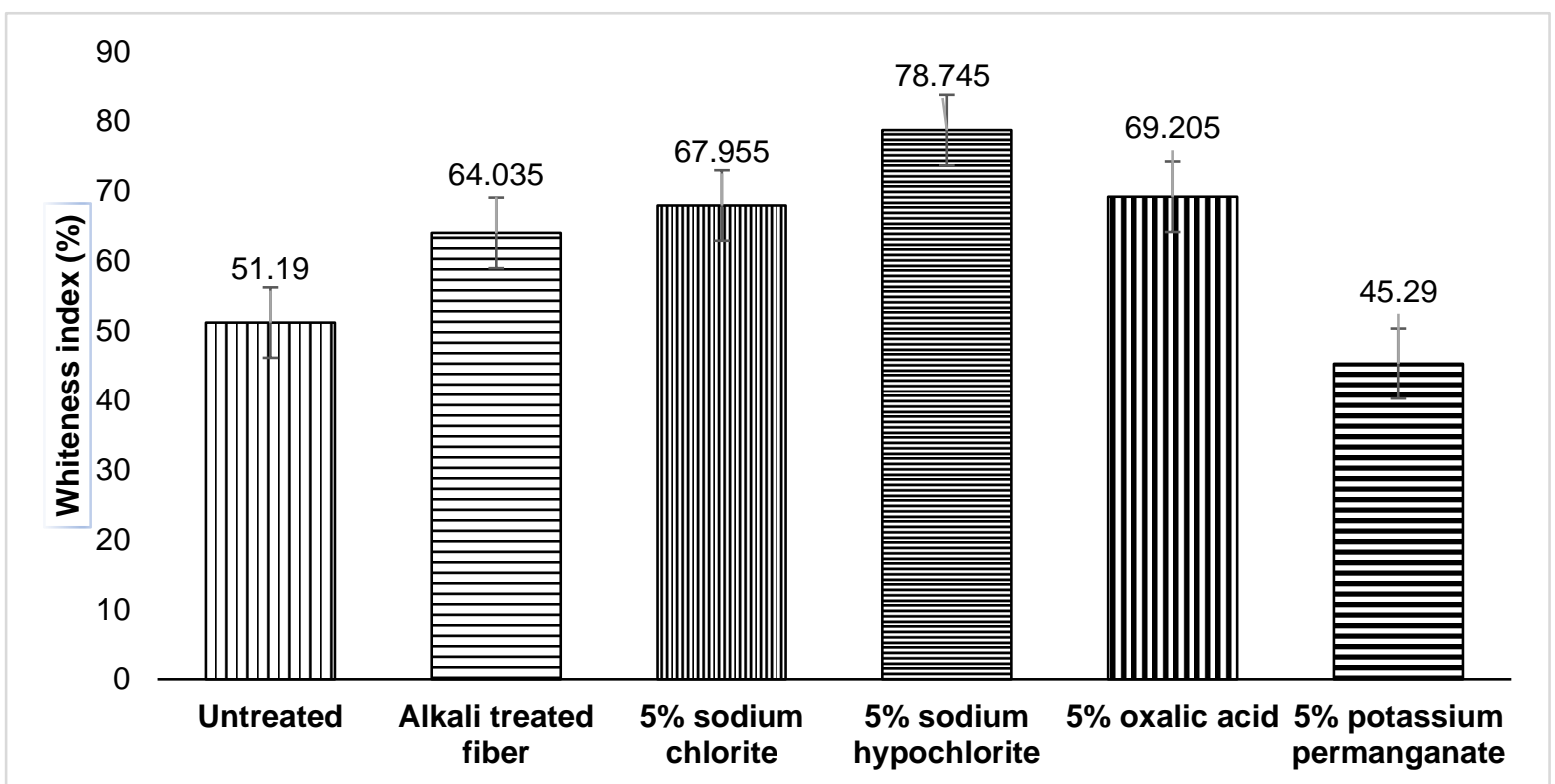

Figure 3: Whiteness index of nanocrystalline cellulose (NCC) at a different percentage of sodium hypochlorite

\subsection{Functional group analysis using FTIR}

The FTIR spectra of cellulose fibers obtained from Leucaena leucocephala fiber using different bleaching agents were compared with reference sample in Figure 4 . Two main absorption bands in two wave number regions of 3500 to $2800 \mathrm{~cm}^{-1}$, and 1740 to $600 \mathrm{~cm}^{-1}$. The presence of peaks of on the spectra of cellulose samples from Leucaena leucocephala fiber corresponds to bands of microcrystalline cellulose. Meanwhile, the differences in absorption bands intensities and appearance of new peaks in spectra of cellulosic fibers were observed.

Identification of the absorption bands is following, the broad observed peaks in the wave number range of $3340-3100 \mathrm{~cm}^{-1}$ was attributed to the $\mathrm{O}-\mathrm{H}$ stretching vibration of the hydrogen-bonded hydroxyl groups in the cellulose molecules (Song et al., 2019; Zheng et al., 2019). The band at $2900 \mathrm{~cm}^{-1}$ was attributed to the $\mathrm{CH}$ stretching vibration of all hydrocarbon's constituent in cellulose. This type of bands has been appeared in all IR spectra except the sample treated with $5 \%$ of $\mathrm{KMnO}_{4}$.

Typical bands assigned to cellulose were observed in the region of $1740-600$ $\mathrm{cm}^{-1}$. The peak located at $1735 \mathrm{~cm}^{-1}$ was corresponding to the acetyl groups and 
ironic esters of the hemicellulose and the ester linkages of the carboxylic groups of the ferulic and p-coumaric acid in lignin and hemicellulose (Song et al., 2019). The effectiveness of bleaching agents used during the bleaching process can be determined by the absence of this peak. From Figure 4, it was observed that this peak was absent when Leucaena leucocephala fiber was treated with sodium chlorite, sodium hypochlorite, and potassium permanganate, but presented in fiber treated with oxalic acid. Thus, it showed that bleaching with oxalic acid is not effective in removing the hemicellulose component in the fiber.

This result was also supported by the results obtained from the chemical composition analysis, in which it was observed that hemicellulose was not completely removed after bleaching treatment with oxalic acid. Oxalic acid has many roles as a bleach, metal polish, and stain remover. Oxalic acid is frequently recommended and used where a comparatively mild bleaching action (Laboratory, 1948). However, in this study, it showed that the mild bleaching provided by oxalic acid was not effective to remove hemicellulose from the Leucaena leucocephala fiber.

In addition, the absorption bands at $1512 \mathrm{~cm}^{-1}$ in the FTIR spectrum was assigned to the aromatic skeletal vibrations of lignin (llyas, Sapuan, \& Ishak, 2017; Song et al., 2019; Tripathi, Ferrer, Khan, \& Rojas, 2017). From Figure 4, this peak was disappeared in the IR spectra of Leucaena leucocephala fiber treated with 5 wt.\% sodium hypochlorite. This absence of peak indicates the rupture of bonds in lignin structure.

The absorption peaks at $1162 \mathrm{~cm}^{-1}$ and $1034 \mathrm{~cm}^{-1}$ were presented in all samples and correspond to the stretching vibration of the $\mathrm{C}-\mathrm{O}-\mathrm{C}$ bonds in the 1,4glycosidic links linkages of the d-glucose units in cellulose, which were interpreted as typical for a cellulose structure (Luzi et al., 2019). Moreover, the peak at approximately $1639 \mathrm{~cm}^{-1}$ in the FTIR spectrum (Figure 4) was attributed to the $\mathrm{H}-\mathrm{O}-\mathrm{H}$ stretching vibration of the adsorbed water due to the hydroxyl groups in cellulose (Zheng et al., 2019), whereas the peak at $898 \mathrm{~cm}^{-1}$ represented the $\mathrm{C}_{1}-\mathrm{H}$ deformation of cellulose (Camacho et al., 2017). Lastly, the peak around 898, 1050, 1165, 1319, 1380, and $1430 \mathrm{~cm}^{-1}$ were associated with the $\mathrm{C}-\mathrm{H}$ rocking vibrations, C-O stretching, C-O-C asymmetric valence vibration, $\mathrm{C}-\mathrm{H}_{2}$ rocking vibration, and $\mathrm{C}-\mathrm{H}_{2}$ deformation vibration, respectively, where these peaks are referred to cellulose form of the carbohydrate 
(llyas et al., 2017). The peaks of $898 \mathrm{~cm}^{-1}$ were present in all samples except for fiber treated with oxalic acid and potassium permanganate

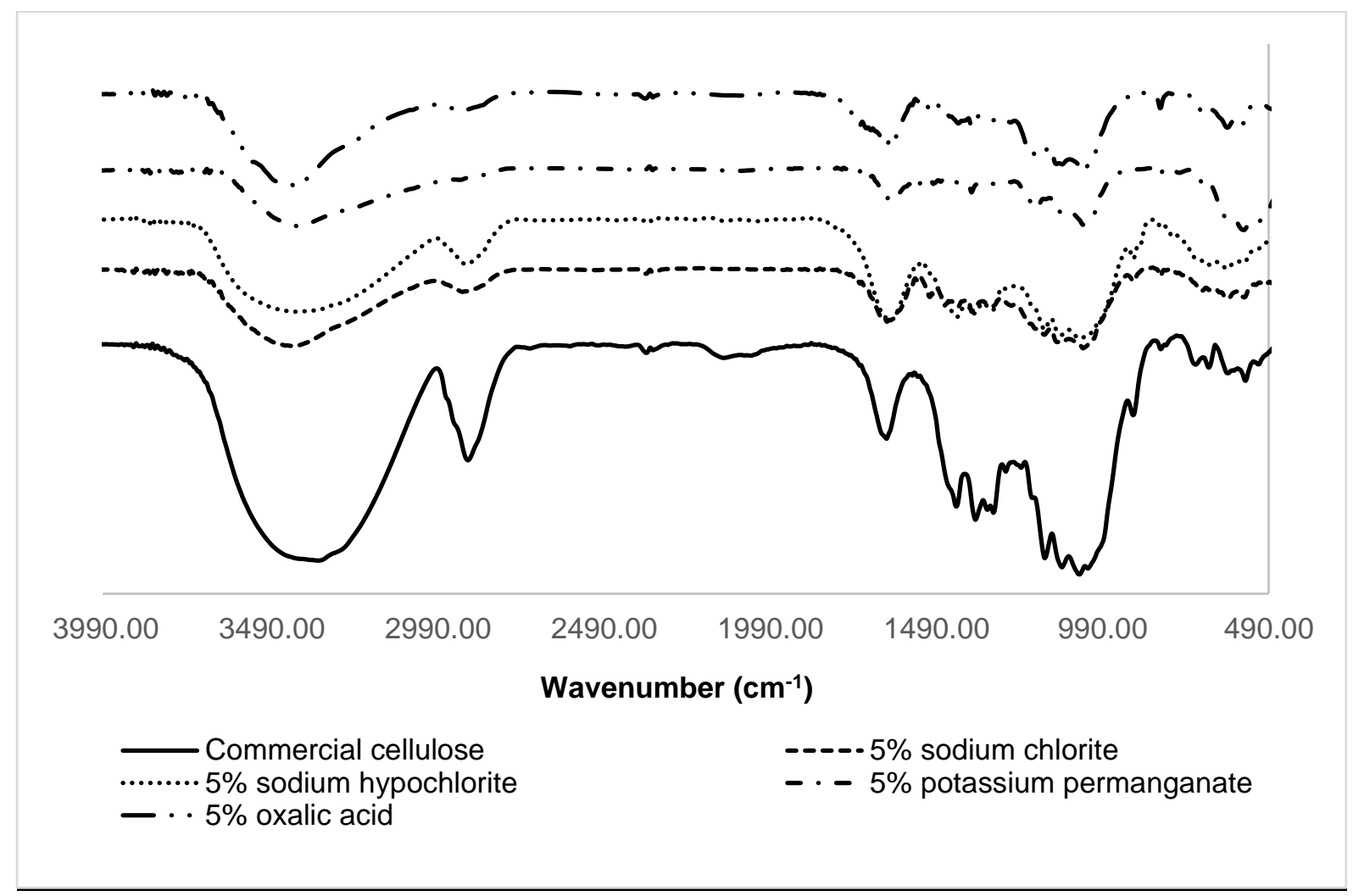

Figure 4: FTIR spectra of all samples

\section{Conclusions}

The cellulose was successfully isolated from Leucaena leucocephala pods via the alkaline and bleaching process. This research presents the results of FTIR spectroscopic comparative study of cellulosic fibers extracted using different bleaching agents with reference sample of microcrystalline cellulose. The spectra obtained presented that cellulose obtained from Leucaena leucocephala pods using $\mathrm{NaClO}$ during bleaching has a similar functional group with the reference sample of microcrystalline cellulose. The chemical composition and whiteness index show that cellulose obtained by bleaching with $\mathrm{NaClO}$ has the highest cellulose composition and whiteness index, which was $89.37 \%$ and $78.5 \%$, respectively. It concludes that $\mathrm{NaClO}$ was the best bleaching agent in removing hemicellulose and lignin from the fiber resulting in highly purified cellulose. Thus, cellulose can be successfully isolated from Leucaena leucocephala pods, and has a great potential for the starting material to produce nanocrystalline cellulose, which offers wide applications such as in food packing and food additive. 


\section{Acknowledgments}

We are much thankful to Universiti Putra Malaysia for providing necessary facilities under Putra Grant- Putra Graduate Initiative (IPS) with the vote number of 9635400 , and Universiti Kuala Lumpur MICET for providing FTIR analysis to carry out the study. Aridi A. S. is grateful to Universiti Tun Hussein Onn Malaysia (UTHM) for the scholarship.

\section{Declaration of conflicting interests}

All the authors declare no conflicts of interest in preparing this article

\section{References}

Adnan, H. (2012, December 4). Changing plantation landscape with alternative cash crop? Business, The Star. Retrieved from https://www.thestar.com.my/business/business-news/2012/12/04/changingplantation-landscape-with-alternative-cash-crop

Aini, N., Ab, N., Husin, M., Yury, N., Othman, M., \& Shariff, Z. M. (2019). Cellulose isolation from Leucaena Leucocephala seed: Effect on concentration sodium hydroxide. Journal of Academia, 7(2), 36-45.

Aurelia, C., Murdiati, A., \& Ningrum, A. (2019). Effect of Sodium Hydroxide and Sodium Hypochlorite on the Physicochemical Characteristics of Jack Bean Skin ( Canavalia ensiformis ). Pakistan Journal of Nutrition, 18(2), 193-200. https://doi.org/10.3923/pjn.2019.193.200

Camacho, M., Regina, Y., Ureña, C., Lopretti, M., Carballo, L. B., Moreno, G., ... Baudrit, V. (2017). Synthesis and Characterization of Nanocrystalline Cellulose Derived from Pineapple Peel Residues. J.Renew.Mater, 5(July), 271-279. https://doi.org/10.7569/JRM.2017.634117

Hayati, N., Rahman, A., Chieng, B. W., \& Rahman, N. A. (2017). Extraction and Characterization of Cellulose Nanocrystals from Tea Leaf Waste Fibers. Polymers, 9, 1-11. https://doi.org/10.3390/polym9110588

Husin, M., Li, A. R., Ramli, N., Romli, A. Z., Hakimi, M. I., \& Ilham, Z. (2017). Preparation and characterization of cellulose and microcrystalline cellulose 
isolated from waste Leucaena leucocephala seeds. International Journal of Advanced and Applied Sciences Journal, 4(3), 51-58.

Ilyas, R. A., Sapuan, S. M., \& Ishak, M. R. (2017). Isolation and characterization of nanocrystalline cellulose from sugar palm fibres (Arenga Pinnata). Carbohydrate Polymers, 181, 1038-1051. https://doi.org/10.1016/j.carbpol.2017.11.045

Laboratory, U. F. P. (1948). Bleaching wood. Forest Products Laboratory.

Lee, S. J. Y., Ng, W. P. Q., \& Law, K. H. (2018). Properties of Cellulose Extract from Different Types of Oil Palm Biomass Properties of Cellulose Extract from Different Types of Oil Palm. In The Wood and Biofiber International Conference. https://doi.org/10.1088/1757-899X/368/1/012049

Luzi, F., Puglia, D., Sarasini, F., Tirillò, J., Ma, G., Zuorro, A., .. Torre, L. (2019). Valorization and extraction of cellulose nanocrystals from North African grass: Ampelodesmos mauritanicus ( Diss ). Carbohydrate Polymers Journal, 209(October 2018), 328-337. https://doi.org/10.1016/j.carbpol.2019.01.048

Musa, A., Ahmad, M. B., \& Hussein, M. Z. (2017). Acid Hydrolysis-Mediated preparation of Nanocrystalline Cellulose from Rice Straw. International Journal of Nanomaterials, Nanotechnology and Nanomedicine, 3, 51-56.

Plermjai, K., Boonyarattanakalin, K., \& Mekprasart, W. (2018). Extraction and characterization of nanocellulose from sugarcane bagasse by ball-millingassisted acid hydrolysis. In International Conference on Science and Technology of Emerging Materials (Vol. 020005).

Soltan, Y. A., Morsy, A. S., Lucas, R. C., \& Abdalla, A. L. (2017). Potential of mimosine of Leucaena leucocephala for modulating ruminal nutrient degradability and methanogenesis. Animal Feed Science and Technology, 223, 30-41. https://doi.org/10.1016/j.anifeedsci.2016.11.003

Song, K., Zhu, X., Zhu, W., \& Li, X. (2019). Preparation and characterization of cellulose nanocrystal extracted from Calotropis procera biomass. Bioresources and Bioprocessing, 6. https://doi.org/10.1186/s40643-019-0279-z

Tripathi, A., Ferrer, A., Khan, S. A., \& Rojas, O. J. (2017). Morphological and Thermochemical Changes upon Autohydrolysis and Microemulsion Treatments 
of Coir and Empty Fruit Bunch Residual Biomass to Isolate Lignin-Rich Microand Nano fi brillar Cellulose. ACS Sustainable Chem. Eng., 5(3), 2483-2492. https://doi.org/10.1021/acssuschemeng.6b02838

Xu, F., Yu, J., Tesso, T., Dowell, F., \& Wang, D. (2013). Qualitative and quantitative analysis of lignocellulosic biomass using infrared techniques: A mini-review. Applied Energy, 104, 801-809.

Yen, M., \& Mau, J. (2006). Preparation of fungal chitin and chitosan from shiitake stipes. Fung. Sci., 21, 1-11.

Youcai, Z. (2018). Processes for Leachate Physical and Chemical Treatment Permanganate. In Pollution Control Technology for Leachate from Municipal Solid Waste (pp. 31-183).

Zafar, S. (2019). Agricultural Biomass in Malaysia. Retrieved from https://www.bioenergyconsult.com/agricultural-biomass-in-malaysia/

Zheng, D., Zhang, Y., Guo, Y., \& Yue, J. (2019). Isolation and Characterization of Nanocellulose with a Novel Shape from Walnut (Juglans Regia L.) Shell Agricultural Waste. Polymers, 11. 